\title{
Phacoemulsification of bilateral cataracts in two pet rabbits
}

\author{
Filipe Espinheira Gomes*, Ricardo de Matos and Eric Ledbetter \\ College of Veterinary Medicine, Cornell University, Ithaca, NY, USA
}

\begin{abstract}
Two 3 year-old, healthy, client-owned Lop rabbits presented with bilateral cataracts. After performing a physical examination, bloodwork, ocular ultrasonography and electroretinography, both animals were deemed good surgical candidates for phacoemulsification. Bilateral cataract surgery was performed and both rabbits regained vision in both eyes. Both animals developed post-operative ocular hypertension and one animal developed corneal ulcers immediately after surgery. Both surgical complications resolved with medical management. This case series describes phacoemulsification of bilateral cataracts in 2 companion rabbits and the use of an intraocular lens in 1 rabbit. Surgical treatment of cataracts can be considered as a treatment option whenever a healthy rabbit is visually impaired due to cataracts.
\end{abstract}

Keywords: Cataracts, Encephalitozoon cuniculi, Intraocular lens, Rabbits.

\section{Introduction}

There are several studies using rabbits to study lenticular disorders and cataract surgery options. While some studies use rabbits as an animal model to induce cataracts, others use research rabbits to test new materials or to evaluate complications associated with cataract surgery. Unfortunately, there is very limited information regarding spontaneous cataracts and cataract surgery in pet rabbits (Waters, 1950; Cogan and Donaldson, 1951; Geeraets et al., 1965; Aose et al., 2014; Huang et al., 2015; Peng et al., 2015;).

Cataracts are one of the leading causes for treatable visual impairment and blindness in humans and animals (Glover and Constantinescu, 1997; Pascolini and Mariotti, 2012).

This case report describes the successful treatment of bilateral cataract surgery and the use of an intraocular lens in healthy pet rabbits.

\section{Case Details}

\section{Case 1}

A 3-year-old male Lop rabbit was referred to Cornell University-Hospital for Animals (CUHA) with a 3-4 month history of bilateral cataracts (Fig. 1). The owner perceived that the rabbit became blind 2 weeks prior to presentation.

The referring veterinarian had evaluated the rabbit three months prior for subdued behavior. At that time, the rabbit was diagnosed with a mature cataract in the right eye (OD) and an immature cataract in the left eye (OS). Results of routine hemogram and biochemistry panel were within normal limits. Encephalitozoon cuniculi titers were 0.711 (>0.350: consistent with infection). The animal was referred to CUHA for cataract evaluation.

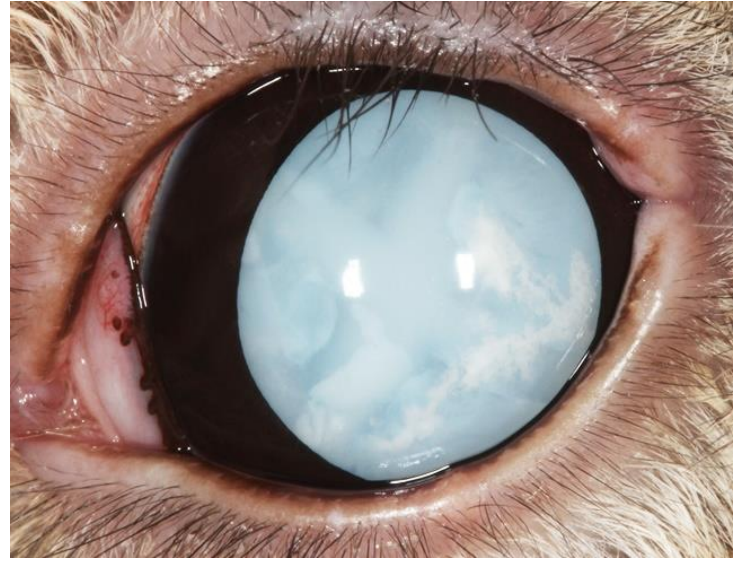

Fig. 1. Mature cataract OS prior to surgery (Case 1).

Upon presentation at CUHA there were no abnormalities noted on physical examination. Biomicroscopy ophthalmic examination revealed mature cataracts in both eyes (OU). Neuro-ophthalmic examination (palpebral, dazzle, pupillary light reflexes) was normal. Intraocular pressure (IOP) was $10 \mathrm{mmHg}$ OU (TONOPEN $®)$.

A flash electroretinography revealed an appropriate photoreceptor response. Ocular ultrasound was normal with exception of bilateral mature cataracts. Hemogram and biochemistry panel were repeated and the results were within the reference range.

Two days prior to surgery, the rabbit was started on topical ciprofloxacin OU q6h, atropine (OU q24h, prednisolone and diclofenac OU q12h.

On the day of surgery, the rabbit was treated topically OU with atropine, flurbiprofen, neomycin-polymixin B-dexamethasone and phenylephrine. 
The animal was pre-medicated with $0.2 \mathrm{mg} / \mathrm{kg} \mathrm{SQ}$ meloxicam, $0.5 \mathrm{mg} / \mathrm{kg}$ IM butorphanol, $1 \mathrm{mg} / \mathrm{kg}$ IM midazolam, $5 \mathrm{mg} / \mathrm{kg}$ IM ketamine and $5 \mathrm{mg} / \mathrm{kg}$ IV enrofloxacin. General anesthesia was induced with $1.1 \mathrm{mg} / \mathrm{kg}$ IV propofol and the rabbit was intubated. General anesthesia was maintained using volatile sevoflurane. Extraocular muscle paralysis was achieved with $0.4 \mathrm{mg} / \mathrm{kg}$ IV cisatracurium.

Surgical preparation and phacoemulsification were performed OU as described elsewhere (Colvard, 2009; Wilkie and Colitz, 2013). The major challenges that were noted with phacoemulsification was that the pupil was not fully dilated and the iris started to prolapse through the incision, which required the use of viscoelastic to reintroduce the iris into the anterior chamber (AC) throughout the surgery. While OD was left aphakic, OS had a 53.5D $12 \mathrm{~mm}$ acrylic intraocular lens (IOL) implanted into the lens capsule (LC) bag.

After surgery, an e-collar was placed and the rabbit recovered uneventfully. Immediate postoperative medications included topical ciprofloxacin OU q6h, prednisolone acetate and diclofenac OU q12h. At the end of the surgical day, IOP were too low to measure OU. The following day the rabbit developed postoperative ocular hypertension $(\mathrm{POH}) \mathrm{OU}(30 \mathrm{mmHg}$ OD; $28 \mathrm{mmHg}$ OS). On ocular exam there was $1+$ flare OD and dorsal chemosis OU. No fluorescein uptake OU was seen after surgery. At that time, brinzolamide OU q8h was started. Oral enrofloxacin $(5 \mathrm{mg} / \mathrm{kg})$ and meloxicam $(0.1 \mathrm{mg} / \mathrm{kg})$ q24h were prescribed for 1 week. The animal's appetite was back to normal immediately post-surgery and all vital parameters remained unchanged. Two days after surgery the chemosis OU had improved, however IOP remained unchanged. The rabbit was sent home on the same therapeutic regimen as prescribed in the previous day. Four weeks postoperatively there was mild perincisional corneal edema and mild dyscoria OU. Neuro-ophthalmic examination was normal OU. The fundus was normal OU. No ulcers were present. IOP was $18 \mathrm{mmHg}$ OD and $22 \mathrm{mmHg}$ OS. The animal continued to be treated with topical medications as previously, except that ciprofloxacin was discontinued. At the time of this recheck, the owners perceived that the rabbit was eating, drinking, urinating and defecating normally.

Eight weeks postoperatively IOPs were normal $(18 \mathrm{mmHg}$ OD; $14 \mathrm{mmHg}$ OS) and the anterior LC was mildly wrinkled (Fig. 2). At this time, all topical medications had been discontinued except diclofenac OU BID.

Six months after surgery the animal presented for a third recheck. No changes were noted on ophthalmic examination since the previous exam and IOP was $15 \mathrm{mmHg}$ OD and $21 \mathrm{mmHg}$ OS. At that time it was recommended to continue diclofenac OU SID.

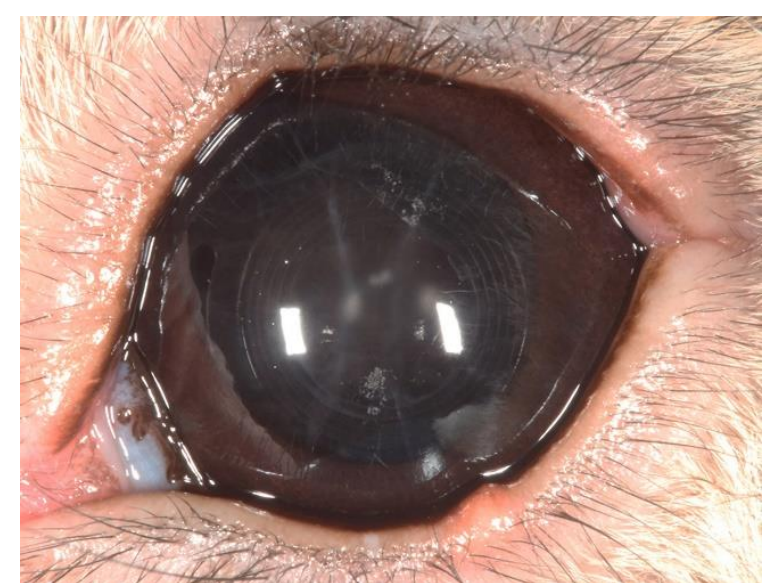

Fig. 2. Pseudophakia OS 8 weeks after surgery. Concentric rings from the optical portion of the IOL can be noted in this image (Case 1).

At the date of last follow-up (one year post surgery via phone conversation with the owner), the rabbit was visual and comfortable OU. The owner also commented that the rabbit would turn his head to preferentially use his pseudophakic eye when looking for the owner or objects of interest.

Case 2

A 3-year-old female spayed Holland Lop rabbit was referred to CUHA with a 3-month history of bilateral cataracts. At that time, the referring veterinarian had diagnosed mature cataracts and started therapy with topical flurbiprofen OU q24h. The owner noted that the rabbit was bumping into objects more frequently, which prompted referral.

Physical examination was unremarkable. Ophthalmic examination revealed bilateral mature cataracts. The neuro-ophthalmic examination was normal. IOP was $11 \mathrm{mmHg}$ OD and $9 \mathrm{mmHg}$ OS (TONOVET $\AA$ ). Biomicroscopy examination revealed bilateral mature cataracts.

A flash electroretinography revealed an appropriate photoreceptor response. Ocular ultrasound was normal with the exception of bilateral mature cataracts. The results of the hemogram and biochemistry panel were within the reference range. Encephalitozoon cuniculi was not detected on serology.

Two days prior to surgery, the rabbit was treated with topical flurbiprofen OU q6h.

On the day of surgery, the rabbit was treated topically OU with tropicamide, flurbiprofen, ofloxacin and phenylephrine. The animal was pre-medicated with $1 \mathrm{mg} / \mathrm{kg}$ SQ meloxicam, $10 \mu \mathrm{g} / \mathrm{kg}$ IM dexmedetomidine, $0.5 \mathrm{mg} / \mathrm{kg}$ IM midazolam, $30 \mu \mathrm{g} / \mathrm{kg}$ IM buprenorphine, $5.3 \mathrm{mg} / \mathrm{kg}$ IV enrofloxacin and $0.017 \mathrm{mg} / \mathrm{kg}$ IV glycopyrrolate. General anesthesia was induced with $0.2 \mathrm{mg} / \mathrm{kg}$ IV midazolam, $5.5 \mathrm{mg} / \mathrm{kg}$ IV ketamine and $0.2 \mathrm{mg} / \mathrm{kg}$ IV alfaxalone, and the rabbit was intubated. General anesthesia was maintained using sevoflurane. 
Extraocular muscle paralysis was achieved with $0.1 \mathrm{mg} / \mathrm{kg}$ IV atracurium.

Surgical preparation and phacoemulsification was performed OU as described elsewhere (Colvard, 2009; Wilkie and Colitz, 2013). Similar surgical challenges were seen as in case 1 . In addition, there were multiple peripheral uveal cysts in the posterior chamber.

Both eyes were left aphakic. The animal recovered uneventfully from surgery.

After surgery, the rabbit was started on topical ofloxacin OU q6h, prednisolone $\mathrm{OU} \mathrm{q} 8 \mathrm{hr}$ and diclofenac OU q8h, oral enrofloxacin $(5 \mathrm{mg} / \mathrm{kg}$ q24h), meloxicam $(0.5 \mathrm{mg} / \mathrm{kg}$ q $24 \mathrm{~h})$, sucralfate $(25 \mathrm{mg} / \mathrm{kg}$ $\mathrm{q} 12 \mathrm{~h})$ and subcutaneous famotidine $(0.5 \mathrm{mg} / \mathrm{kg} \mathrm{q} 24 \mathrm{~h})$. IOP was $10 \mathrm{mmHg}$ OD and $8 \mathrm{mmHg}$ OS 3 hours after surgery.

The following day the rabbit was bright, alert and responsive (BAR). The rabbit appeared comfortable and had a normal appetite. On ophthalmic examination the rabbit had a superficial non-infected corneal ulcer OU. There was 2+flare and cells OU. IOP was $23 \mathrm{mmHg}$ OD and $9 \mathrm{mmHg}$ OS. Fundic examination was normal OU. Later that day, IOP was 40mmHg OD and $3 \mathrm{mmHg}$ OS and the rabbit appeared to be slightly uncomfortable. At that time, aqueocentesis OD was performed followed by $25 \mu \mathrm{g}$ of intracameral TPA. IOP OD immediately after this procedure was $13 \mathrm{mmHg}$. In addition, the animal was started on subcutaneous buprenorphine $(0.02 \mathrm{mg} / \mathrm{kg} \mathrm{SQ} \mathrm{q} 8 \mathrm{~h})$ for 2 days.

Two days after surgery the rabbit was BAR, had a normal appetite and appeared comfortable. On ophthalmic examination there were superficial noninfected corneal ulcers OU. There was 1-2+ flare OU. IOP was $23 \mathrm{mmHg}$ OD and $3 \mathrm{mmHg}$ OS.

Three days after surgery the rabbit remained active with a good appetite and appeared comfortable. On ophthalmic examination there was a small superficial non-infected corneal ulcer OU, 1-2+ flare OU, and IOP was $23 \mathrm{mmHg}$ OD and $2 \mathrm{mmHg}$ OS. The rabbit was sent home on topical ofloxacin OU q6h, diclofenac OU q8h, dorzolamide/timolol OD $\mathrm{q} 8 \mathrm{~h}$ and artificial tears OU q6h. Treatment was continued with oral meloxicam, enrofloxacin and sucralfate for 10 days. In addition, oral tramadol $(5 \mathrm{mg} / \mathrm{kg} \mathrm{q} 8-12 \mathrm{~h})$ was started as needed for pain.

Two weeks after surgery the rabbit presented for a recheck examination. The animal was reported to be active with normal food and water intake and perceived to be visual and comfortable. Ophthalmic recheck examination demonstrated that flare and corneal ulcers were resolved OU. There was a posterior synechia OU and a small amount of fibrin OS. IOP was $11 \mathrm{mmHg}$ OD and $5 \mathrm{mmHg}$ OS. There was anisocoria $(\mathrm{OD}<\mathrm{OS})$ and both fundus were normal. At that time, the rabbit was sent home on topical ofloxacin OU q8h and diclofenac OU q12h.
Four weeks after surgery, no changes had occurred on ophthalmic examination, except that the fibrin OS had resolved. IOP was $12 \mathrm{mmHg}$ OD and $7 \mathrm{mmHg}$ OS. At that time, the animal was sent home on topical diclofenac OU q24h. This animal was lost to follow-up 4 weeks after surgery.

\section{Discussion}

Cataract surgery in companion animals is considered an elective procedure that aims to improve the animals' quality of life. Few case reports have been published regarding unilateral cataract surgery in pet rabbits and most of the current knowledge is based on research models. Cataracts in rabbits have been noted to be congenital, juvenile, age related, inherited, induced and associated with Encephalitozoon cuniculi (Waters, 1950; Cogan and Donaldson, 1951; Geeraets et al., 1965; Gelatt, 1975; Felchle and Sigler, 2002; Munger et al., 2002; Peng et al., 2015). Unfortunately, there is very limited information regarding naturally occurring cataracts and cataract surgery in pet rabbits. Several studies exist using rabbits as an animal model to study lenticular disorders and cataract surgery however these projects use rabbits with induced pathology or test different surgical techniques or materials (Waters, 1950; Cogan and Donaldson, 1951; Geeraets et al., 1965; Nishi et al., 2004; Buehl and Findl, 2008; Aose et al., 2014; Huang et al., 2015).

One case report had intraocular E. cuniculi and the second case report had cataract surgery 2 years after having the fellow eye enucleated due to $E$. cuniculi phacoclastic uveitis. This second report does not provide details about the phacoemulsification procedure performed on this animal (Felchle and Sigler, 2002; Sandmeyer et al., 2011). In the recent past there was a study evaluating the IOL size and dioptric power in pet rabbits, however there was no information regarding the clinical outcome of these animals (Sanchez et al., 2017).

While in the first case the animal had antibodies against E.cuniculi consistent with exposure to the parasite, the second rabbit's serologic test results were negative. Nevertheless, the affected rabbit did not have neurological abnormalities or phacoclastic uveitis as often seen in clinically affected animals (Sandmeyer $e t$ al., 2011). The cause for the cataracts could not be determined for the rabbits in these two cases.

In our first case, an IOL was placed in one eye. Even though there were no commercially available IOL designed for rabbits at the time of the surgery, one study suggested that emmetropia in young rabbits can be achieved with a 48.5-59.67D IOL (Valinhos et al., 2012). This is within the range of IOL strength that is required for emmetropia after lens extraction in cats (Gilger et al., 1998a, 1998b). In a recent study, emmetropia was achieved in pet rabbits that received a 58D IOL after phacoemulsification (Sanchez et al., 
2017). In addition to the advantages of improved vision in pseudophakic eyes, there are several studies suggesting that posterior capsular opacification (PCO), a common complication after cataract surgery in humans and animals, may be mitigated by the IOL. This is supported by several studies that showed that the lens design, material and chemical properties could decrease PCO (Nishi et al., 2004; Buehl and Findl, 2008; Gift et al., 2009).

Despite the limited knowledge in regards to the ideal properties for an IOL in rabbits, it was decided to use an IOL in one eye to help improve vision and prevent PCO. Conversely, placing an IOL is not without risk. If an animal develops an extensive lens regrowth, an intracapsular IOL may be pushed out of the lens capsular bag, which may result in negative consequences for the eye (Williams, 2012).

It has been argued that leaving an animal aphakic may in fact help prevent PCO. Exposure of the posterior LC to the aqueous humor has inhibitory effects on lens fibroblasts (Burke et al., 1983; Gwon et al., 1993; Kurosaka and Nagamoto, 1993; Aose et al., 2014). Normal rabbits are mildly hyperopic. When rabbits are left aphakic, it results in 15-20D of hyperopia (Herse, 2005; Gwon, 2006).

In humans, the ease with which an aphakic correction is accepted appears to vary in inverse proportion to the patient's visual needs. In addition, the consequences of aphakic vision can be overcome overtime (1952). The same outcome should be expected in pet rabbits, as their visual needs are mostly needed to avoid their predators, or physical challenges in their living environment.

In previous studies, it has been shown that rabbits can synthesize new lens fibers after phacoemulsification whenever some residual lens epithelial cells are left in the LC (Gwon et al., 1989; Gwon, 2006). This concern is likely associated with the age of rabbits that are used in cataract surgery research (6-12 weeks old). Typically, younger rabbits have a greater postoperative inflammatory response, PCO and lens regenerative growth in comparison with older rabbits (Gwon, 2008). In the cases reported here, lens epithelial regrowth was not seen. This may be due to the age of the animals presented here, length of the follow-up, method of cataract extraction, the amount of residual cortical tissue left behind, and at least in one eye, the presence of an IOL in the capsular bag (Gwon, 2008). This may also be related to the fact that in contrast to experimental phacoemulsification studies, all lenses in these 2 cases had cataracts.

A few challenges were encountered when performing cataract surgery in these rabbits. Iris prolapse experienced in both cases described here was probably associated with the natural bowing of the iris anteriorly.
In addition, the presence of peripheral uveal cysts in the posterior chamber of the second case exacerbated this surgical challenge. Nevertheless, this complication was successfully managed using viscoelastics to carefully manipulate the uveal tissues. Another challenge that was noted in both these rabbits was $\mathrm{POH}$. The extent of such phenomenon may be associated with intraocular inflammation, capsulorrhexis size, surgical technique and residual viscoelastic material in the AC (Lagreze et al., 1996; Laurell et al., 1997; Cekic and Batman, 1999; Rainer et al., 2000; Klein et al., 2011). Nevertheless, both animals had a positive response to short-term antiglaucoma therapy and were able to discontinue these medications.

Anisocoria was seen in the follow up recheck in one animal. This was likely due to the presence of a posterior synechia, however we could not rule whether there was a low-grade uveitis that was not detected on biomicroscopy.

Finally, it has been reported in the past that intraocular sarcomas can occur in rabbits when the lens capsule ruptures. As a capsulorrhexis is required to remove the cataractous lens, long-term follow-up in a larger number of rabbits undergoing phacoemulsification is required to determine if this is going to be a real concern in these animals (McPherson et al., 2009; Dickinson et al., 2013; Lempp et al., 2014).

It is commonly suggested that blind rabbits can lead an apparently normal life, being able to navigate around their environment, feed and interact with fellow cagemates without difficulty (Williams, 2012). As the pet rabbit numbers increase and people become more aware of subtle changes in their pet's behavior, it is possible that this dogmatic observation may be questioned.

This is the first detailed description of bilateral phacoemulsification in 2 rabbits and the use of an IOL in one rabbit eye. Further studies are warranted to determine the effectiveness of this procedure in pet rabbits and to determine the features of an ideal IOL for this species.

\section{Conflict of interest}

The authors declare that there is no conflict of interests.

\section{References}

1952. The Adjustment to Aphakia. Am. J. Ophthalmol. 35, 118-122.

Aose, M., Matsushima, H., Mukai, K., Katsuki, Y., Gotoh, N. and Senoo, T. 2014. Influence of intraocular lens implantation on anterior capsule contraction and posterior capsule opacification. J. Cataract Refract. Surg. 40, 2128-2133.

Buehl, W. and Findl, O. 2008. Effect of intraocular lens design on posterior capsule opacification. J. Cataract Refract. Surg. 34, 1976-1985. 
Burke, J., Foster, S. and Herschler, J. 1983. AqueousHumor as a Modulator of Growth in FibroblastCultures. Current Eye Res. 2, 835-841.

Cekic, O. and Batman, C. 1999. Effect of capsulorhexis size on postoperative intraocular pressure. J. Cataract Refract. Surg. 25, 416-419.

Cogan, D.G. and Donaldson, D.D. 1951. Experimental Radiation Cataracts .1. Cataracts in the Rabbit Following Single X-Ray Exposure. AMA. Arch. Ophthalmol. 45, 508-522.

Colvard, D.M. 2009. Achieving Excellence in Cataract Surgery: A step by step approach.

Dickinson, R., Bauer, B., Gardhouse, S. and Grahn, B. 2013. Intraocular sarcoma associated with a rupture lens in a rabbit (Oryctolagus cuniculus). Vet. Ophthal. 16, 168-172.

Felchle, L.M. and Sigler, R.L. 2002. Phacoemulsification for the management of Encephalitozoon cuniculi-induced phacoclastic uveitis in a rabbit. Vet. Ophthal. 5, 211-215.

Geeraets, W.J., Harrel, W., Guerry, D., Ham, W.T. and Mueller, H.A. 1965. Aging Anomalies and Radiation Effect of Rabbit Lens. Acta Ophthalmol. 43, 3-21.

Gelatt, K.N. 1975. Congenital Cataracts in a Litter of Rabbits. J. Am. Vet. Med. Assoc. 167, 598-599.

Gift, B.W., English, R.V., Nadelstein, B., Weigt, A.K. and Gilger, B.C. 2009. Comparison of capsular opacification and refractive status after placement of three different intraocular lens implants following phacoemulsification and aspiration of cataracts in dogs. Vet. Ophthalmol. 12, 13-21.

Gilger, B.C., Davidson, M.G. and Colitz, C.M.H. 1998a. Experimental implantation of posterior chamber prototype intraocular lenses for the feline eye. Am. J. Vet. Res. 59, 1339-1343.

Gilger, B.C., Davidson, M.G. and Howard, P.B. 1998b. Keratometry, ultrasonic biometry, and prediction of intraocular lens power in the feline eye. Am. J. Vet. Res. 59, 131-134.

Glover, T.D. and Constantinescu, G.M. 1997. Surgery for cataracts. Vet. Clin. North Am. Small Anim. Pract. 27, 1143-1173.

Gwon, A. 2006. Lens regeneration in mammals: A review. Surv. Ophthalmol. 51, 51-62.

Gwon, A. 2008. The Rabbit in Cataract/IOL Surgery. In: Animal Models in Eye Research, pp: 184-204.

Gwon, A., Enomoto, H., Horowitz, J. and Garner, M.H. 1989. Induction of Denovo Synthesis of Crystalline Lenses in Aphakic Rabbits. Exp. Eye Res. 49(6), 913-926.

Gwon, A., Gruber, L.J. and Mantras, C. 1993. Restoring Lens Capsule Integrity Enhances Lens Regeneration in New-Zealand Albino Rabbits and Cats. J. Cataract Refract. Surg. 19, 735-746.
Herse, P. 2005. Effects of hyperglycaemia on ocular development in rabbit: refraction and biometric changes. Ophthalmic Physiol. Opt. 25, 97-104.

Huang, L.C., Salvador-Silva, M., Hunter, T. and Gwon, A. 2015. Evaluation of a New Compact Phacoemulsification System for Extracapsular Lens Extraction during Cataract Surgery in a Rabbit Model. Invest. Ophthalmol. Vis. Sci. 56(7), 1899.

Klein, H.E., Krohne, S.G., Moore, G.E. and Stiles, J. 2011. Postoperative complications and visual outcomes of phacoemulsification in 103 dogs (179 eyes): 2006-2008. Vet. Ophthalmol. 14(2), 114120.

Kurosaka, D. and Nagamoto, T. 1993. Inhibitory effect of TGF-beta 2 in human aqueous humor on bovine lens epithelial cell proliferation. Invest. Ophthalmol. Vis. Sci. 35, 3408-3412.

Lagreze, W.D., Bomer, T.G. and Funk, J. 1996. Effect of surgical technique on the increase in intraocular pressure after cataract extraction. Ophthalmic Surg. Lasers 27, 169-173.

Laurell, C.G., Wickstrom, K., Zetterstrom, C. and Lundgren, B. 1997. Inflammatory response after endocapsular phacoemulsification or conventional extracapsular lens extraction in the rabbit eye. Acta Ophthalmol. Scand. 75, 401-404.

Lempp, C., Henningsen, G., Pfeifer, H., Fehr, M., Wagner, F., Kostlinger, S. and Wohlsein, P. 2014. Intraocular sarcoma in a pet rabbit (Oryctolagus cuniculus f. dom). Kleintierpraxis 59, 145-149.

McPherson, L., Newman, S.J., McLean, N., McCain, S., Vemulapalli, R., Kania, S. and Dubielzig, R.R. 2009. Intraocular sarcomas in two rabbits. J. Vet. Diagn. Invest. 21, 547-551.

Munger, R.J., Langevin, N. and Podval, J. 2002. Spontaneous cataracts in laboratory rabbits. Vet. Ophthalmol. 5, 177-181.

Nishi, O., Nishi, K. and Osakabe, Y. 2004. Effect of intraocular lenses on preventing posterior capsule opacification: Design versus material. J. Cataract Refract. Surg. 30, 2170-2176.

Pascolini, D. and Mariotti, S.P. 2012. Global estimates of visual impairment: 2010. Br. J. Ophthalmol. 96, 614-618.

Peng, X.W., Roshwalb, S., Cooper, T.K., Zimmerman, H. and Christensen, N.D. 2015. High incidence of spontaneous cataracts in aging laboratory rabbits of an inbred strain. Vet. Ophthalmol. 18, 186-190.

Rainer, G., Menapace, R., Findl, O., Georgopoulos, M., Kiss, B. and Petternel, V. 2000. Intraocular pressure after small incision cataract surgery with Healon5 and Viscoat. J. Cataract Refract. Surg. 26, 271-276.

Sanchez, R., Becker, R., Dawson, C., Escanilla, N. and Lam, R. 2017. Calculation of posterior chamber intraocular lens (IOL) size and dioptric power for 
use in pet rabbits undergoing phacoemulsification. Vet. Ophthalmol. 20, 242-249.

Sandmeyer, L.S., Bauer, B.S. and Grahn, B.H. 2011. Diagnostic Ophthalmology Ophtalmologie diagnostique. Can. Vet. J. 52, 327-328.

Valinhos, M.A.R., Ranzani, J.J.T., Rodrigues, A.C.L. and Brandao, C.V.S. 2012. Measurements of ocular bulb and calculation of the dioptric power of intraocular lenses in rabbits. Arq. Bras. Med. Vet.
Zoo. 64, 58-62.

Waters, J.W. 1950. Biochemical and Clinical Changes in the Rabbit Lens during Alloxan Diabetes. Biochem. J. 46, 575-578.

Wilkie, D. and Colitz, C. 2013. Surgery of the Lens, In: Vet Ophthal, $5^{\text {th }}$ ed. Ames, Iowa: Wiley-Blackwell, pp: 1234-1286.

Williams, D.L. 2012. Ophthalmology of Exotic Pets. Chichester, West Sussex : Wiley-Blackwell, UK. 